\title{
Reducing the Effects of Water Hammer Phenomenon in Pipelines by Changing the Closing Rate of Line Break Valve (LBV)
}

DOI:10.36909/jer.13667

\author{
Mohammad Reza Boroomand*, Nasim Safar Razavizadeh ${ }^{* *}$, Ahmad Eshghi** \\ *Department of civil Engineering, Tafresh University, Tafresh 39518 79611, Iran \\ ${ }^{*}$ Department of Research \& Development, Omran Mohit Zist Consulting Engineers Co., Tehran, Iran \\ *Corresponding Author: boroomand@tafreshu.ac.ir
}

\begin{abstract}
Line break valves in pipelines are using to prevent environmental hazards caused by the entry of the fluid into the surrounding. The operation of these valves leads to sudden changes in pressure and velocity, resulting in the occurrence of the water hammer phenomenon. The water hammer pressure will cause serious problems such as the destruction of pipelines and transmission line equipment and tools. Due to the salinity of water, when a fracture occurs, the amount of water that enters the surrounding is environmentally essential, so the use of several LBVs is vital. This paper investigated a water transmission line with a total length of $337 \mathrm{~km}$ that transfers saline water from Khoor Moosa to Azadegan plain. This study discussed the closing of the valve at different rates and the solution to reduce its destructive effects. WaterGEMS V8i software and Hammer V8i software are respectively using to perform a steady flow simulation and damping flow analysis for this phenomenon. The results obtained from the steady-state flow simulation is the initial conditions in the damping flow calculations. Then, by reducing the closing rate of the valve in 6 different scenarios, the volume of air chambers decreased. Finally, the results led to creating a linear relationship between the valve closing rate and the capacity of the air chamber. The optimal model for this rate depends on reducing the construction cost as well as the environmental hazards caused by discharged water.
\end{abstract}

Keywords: Line break valve, Water hammer, Valve closing rate, Air chamber.

\section{1- INTRODUCTION}

Transmission lines refer to a set of facilities, including pipes, fittings, and valves, that are constructed to transfer fluids (liquids and gases) from one point to another. Some hazards such as floods, earthquakes, lightning, aerial bombardment, theft, and sabotage can cause problems for these pipelines. These hazards may lead to pipe fracture and fluid loss, as well as environmental hazards due to fluid entering the environment. Pipelines are usually designed based on hydraulic calculations of steady flow conditions and friction head loss using the maximum working pressure plus reliability. Whereas in each network, flow starting from a pump and ending to a 
valve produces a damping flow. Many sudden events such as a pump shutdown, unstable control, water fluctuations in the tanks, quick closure of the valves, or any sudden flow stop can cause to water hammer. The pressure caused by this phenomenon occurs in the whole pipeline system, which will lead to fatigue or fracture of the pipeline [Hawkins, 2017]. When a pipeline fracture occurs, the line break valve closes to prevent water from leaving the system. The quick closure of LBVs makes changes in pressure and velocity in the line, which leads to the water hammer phenomenon. Also, if the closing rate is low, it will cause more environmental hazards by entering more water into the surrounding. Hydraulic simulation of pipeline flow under damping conditions requires the study and analysis of water hammer in pumps and valves [Mylapilli et al., 2015].

Tools and equipment in transmission systems for controlling or reducing water hammer effects are different depending on the type of transmission system, size of the project, type of pipe and fluid, water hammer pressure magnitude, the importance of the project in terms of possible damage, how to operate, and finally the construction costs of the protection system. In some cases, a steel plate is used to secure the pipe against water hammer pressure. The plate is resistant to the operating pressure of the system, but the strength of it is less than the final resistance of the pipe. So, the steel plate breaks before the main pipe, and with the withdrawal of some water from the system, the water hammer pressure decreases. Another method is the using of double orifice air valves that have two large and small orifices. The function of the large orifice is to open with a pressure drop in the pipeline and bring air into the system. As the pressure in the pipeline increases, the large orifice blocks, and the air collected inside the pipeline escapes through the small orifice. Some systems uses a stand pipe that sends water into the pipeline to prevent the pressure from decreasing and expels it from the system so that the pressure does not increase to an unauthorized value. Another system is drainage tank that injects water into the main pipe to prevent the water column separation. This tank is filled by the water flow of the pipe next to the device passage (while the float is ready to accept the inlet flow due to the low water level in the water tank). Also the surge tanks can enter water into the pipeline during the water hammer phenomenon and can flow back into the tank. By reducing the operating pressure, water enters the surge tank to prevent unauthorized pressure drop, and by increasing the system pressure, water enters the tank. The tank here plays the role of reducing the water hammer wave pressure. Among water hammer control equipment, the air chamber provides the most facilities against the water hammer phenomenon. This device works in both negative and positive pressure states, which means that it both prevents the water column separation and absorbs the increase in pressure. Of course, the cost of design, installation, and maintenance of this device is much higher than other systems and also needs skilled operators to utilize [No.517, 2010].

During these years, with the advancement of computer technologies, water hammer simulation in water transmission and distribution systems have made significant progress. D. Covas et al. presented the first part of an experimental analysis for the mathematical simulation of this phenomenon [Covas et al., 2004]. Again, in 2005 D. Covas et al. presented the second part of their study by making comparisons [Covas et al., 2005]. Another research performed a hydraulic analysis of the flow using the method of characteristics and experimental approaches [Wichowski, 2006]. M.H. Afshar and M. Rohani presented an implicit method of characteristics 
to reduce defects and limitations of the typical type of it (MOC). The proposed method allows the arbitrary combination of devices in the pipeline system. This method solves two examples of transient flow problems due to valve closing and pump system failure [Afshar et al., 2008]. In 2014, M. A. Bouaziz et al. presented their study on the effect of water hammer in distribution network water quality, using FORTRAN and ABAQUS software [Bouaziz, 2014]. C. Wang and JD. Yang presented water hammer simulations as a combination of the Method of Characteristics (MOC) and Method of Implicit (MOI) and used this coupling method to study transient processes at two hydroelectric stations [Wang, C, 2015]. A paper redesigned existing steel piping systems in 2017 to control the positive and negative waves caused by water hammer. For this purpose, a polymer branched gate (penstock) is added in the sensitive areas of the existing system [Triki, 2017].

As mentioned, the most common equipment to control the effects of water hammer phenomenon in the design of pipelines are air chambers. These systems can be used in all conditions (negative and positive pressure) and provide the most facilities to control this phenomenon. Due to the high cost of air chamber equipment, six different scenarios are defined in this study based on the closing rates of line break valves to reduce the volume of these tanks. By reducing this rate, the severity of the water hammer pressure will reduce, and consequently, the required tank volume and associated costs will be decreased. The objectives of this study were to reduce construction cost by changing air chamber dimensions considering the amount of discharged water and environmental hazards. In the following, a relationship between the valve closing rate and air chamber volume helps to find the optimal point for cost and risks due to the closing of the valve.

\section{2- MATERIALS AND METHODS}

\section{2-1- Line Break Valves (LBV)}

Line Break valves (LBV) are used to prevent the emptying of storage tanks during the burst and breaking of transmission lines. LBVs are often of the butterfly type and sometimes of the needle type, and their actuator system consists of a hydraulic jack, a lever, and a weighted part instead of a gearbox. The hydraulic jack holds the weighted part at the top by applying force to the lever connected to the valve shaft so that the valve opens completely. A sensitive system to fluid velocity monitors velocity changes in the inlet of the valve frequently. By increasing the fluid velocity in the set range (E.g., due to a pipeline fracture), the system opens the drain orifice of the hydraulic jack, then the weighted part is released and closes the valve. These valves should have three main properties:

- Move 90 degrees.

- Make a low pressure loss

- Do not need any electrical power to close the valve

A significant point about the performance of this type of valves in comparison with other electrical protection valves is that the steering circuit of these valves is entirely mechanical. Therefore, in the event of disasters such as floods, earthquakes, lightning, and aerial 
bombardments, which cause power outages, these valves do not need any electrical power to be activated. Also, there is no risk of electric shock or problems related to the maintenance of electrical systems or charging batteries, which requires a lot of time and money [No.529, 2010].

The sudden closing of these valves causes a change in pressure and velocity and creates a damping flow throughout the system. Figure 1 shows the damping phenomenon when the valve suddenly closes. According to the figure below, this flow occurs at the period $T_{t}$ and the pressure is expressed as a function of time. When the valve starts to close, the pressure in the system is equal to $\mathrm{p}_{\mathrm{i}}$, and after the damping flow occurs, this pressure becomes to $\mathrm{p}_{\mathrm{f}}$. Pressure fluctuations occur between these two steady-state flow conditions. According to the following figure, the maximum and minimum pressure are very different from the initial and final pressure [EL-Turki, 2013].

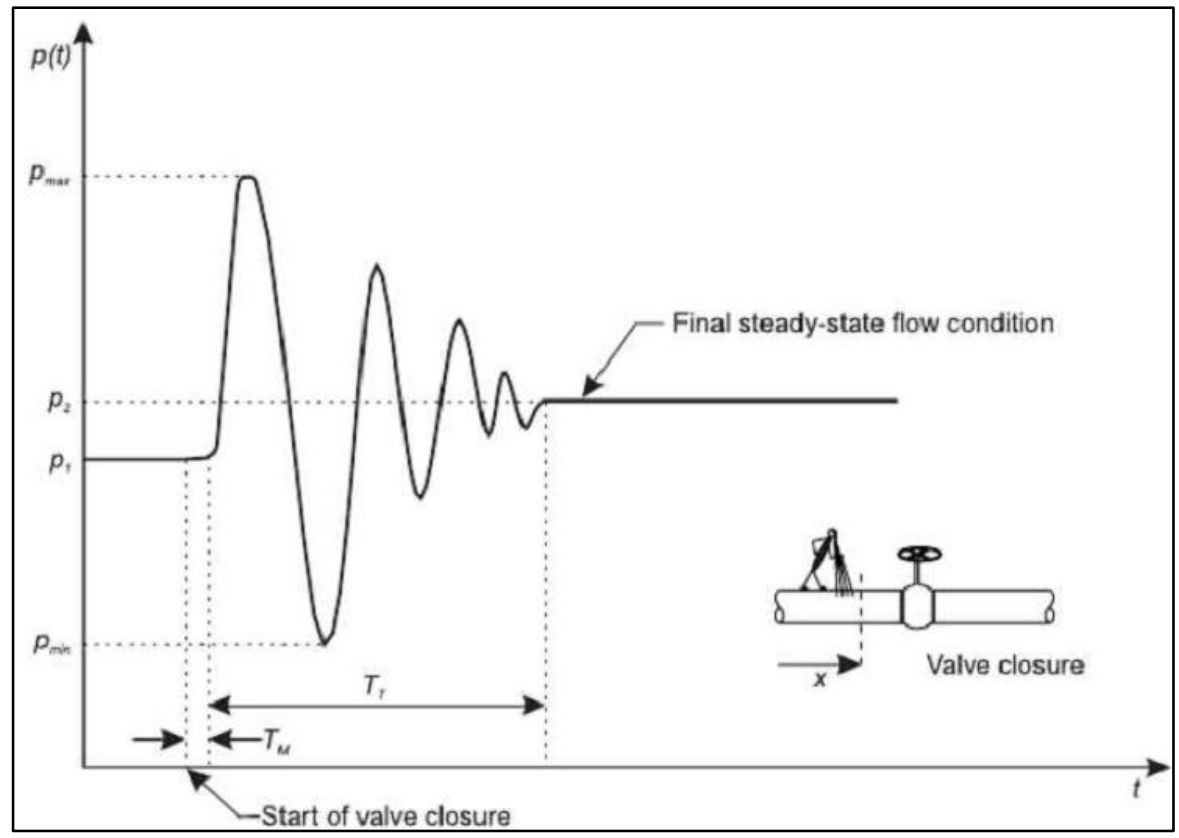

Figure 1- Damping flow phenomenon in sudden closure of the valve [EL-Turki, 2013]

\section{2-2- Software for Hydraulic Modeling of Transmission Line and Water Hammer}

There are various available software for modeling and hydraulic analysis of water distribution networks and transmission lines that some of the most important of them are WaterCAD, KYPIPE, MIKENET, EPANET, and WaterGEMS. In general, in most software, the designer must make a series of manual and preceding calculations on the map for his initial inputs, and finally, by extracting the necessary geographical information from analog maps, refer it to a processor software. Among these applications, the ability to combine WaterGEMS with other software (Microsoft Excel, AutoCAD, ArcGIS) adds to its potential and efficiency, so this study 
uses this application to model the transmission line. WaterGEMS has the ability to support the results of ArcGIS and can easily input the geographic calculations into the analyzing process.

In order to model and analyze the water hammer phenomenon, the HAMMER software was chosen from several available software such as HAMMER, ART, PIPENET, HYTRAN, AFT IMPULSE, FLOWMASTER. The most important reason for choosing this software is its ability to be connected with WaterGEMS, which can easily import the results of hydraulic modeling of the pipeline into HAMMER to prevent human error and save time.

\section{2-2-1- WaterGEMS v8i software}

WaterGEMS provides a suitable and user-friendly application for modeling water distribution networks. This software improves our knowledge about infrastructure's behavior as a system, its reactions to different operational strategies, and the way of growing it in case of rising demand. OpenFlow WaterGEMS is used in a flexible multi-platform environment, such as fire flow and water quality simulation or criticality and energy cost analysis.

The software abilities include the following applications:

- The software provides an intelligent service for system reliability of the water network when the capability of the network must be evaluated in case system growth is anticipated. This software identifies potential problem areas, accommodates service area growth, and plans capital improvements.

- The software is capable of optimizing operations for system efficiency for complex water systems which are difficult to model. This software is useful in the modeling of pump accurately, optimizing pumping strategies, and planning shutdowns and routine operations to minimize disruption.

- The software provides a reliable asset in renewal decision support in case of replacing water infrastructure. In this situation, the amount of asset-related information that we have to consider can be overwhelming. Some capabilities of this software, such as Pipe Renewal Planner makes it much easy by analyzing and comparing a wide range of variables to prioritize renewal decisions [OpenFlows WaterGEMS, 2020].

\section{2-2-2- Hammer v8i software}

OpenFlows HAMMER is used in water networks including pump or valve that can create the possibility of water hammer phenomenon. This software has an easy-to-use interface to efficiently identify, manage, and mitigate the risks associated with transients.

HAMMER can identify critical points in the system that need protection and facilitate sound system design with the following modeling tools:

- This software focuses on the mitigating surge, not on the modeling process. It means that it can effectively develop the most appropriate strategy for controlling and limiting hydraulic transients.

- This software simulates the transient model precisely to improve the quality of the decisions and decrease the risk of approximating the behavior of protective devices and rotating 
equipment. OpenFlows HAMMER can accurately simulate the impact of a wide range of surge protection devices and rotating equipment, such as pumps and turbines.

Finally, it can easily import CAD and GIS data for improved design productivity in water network modeling [OpenFlows HAMMER, 2020].

\section{2-3- The Case Study}

\section{2-3-1- Location and geometric specifications of the project}

The purpose of this project is to implement a seawater transmission system to convey a total flow rate of $6 \mathrm{~m}^{3} / \mathrm{s}$ from Khoor Moosa to four delivery points. This system has three main lines. Each of the two located reservoirs directs the treated water to a pipeline. These two parallel lines supply the demand of the three first areas 1,2 , and 3 , then continue to the 4 th area through a single line.

The distance between the pump station and the 4th area is $184 \mathrm{~km}$, which in total includes 338 $\mathrm{km}$ of piping. This system includes 29 line break valves and two pump stations with eight centrifugal pumps. Table 1 shows the position of the delivery points.

Table 1- Transmission line specifications

\begin{tabular}{|c|c|c|c|c|}
\hline & Length of the part $(\mathrm{km})$ & Distance $(\mathrm{km})$ & Height (m) & Flow rate $\left(\mathrm{m}^{3} / \mathrm{s}\right)$ \\
\hline Pump station & & 0 & 4.35 & 6 \\
\hline Area 1 & 55 & 55 & 7 & 0.44 \\
\hline Area 2 & 51 & 106 & 11 & 1.23 \\
\hline Area 3 & 47 & 153 & 3.5 & 2.32 \\
\hline Area 4 & 31 & 184 & 3.5 & 2.01 \\
\hline
\end{tabular}

Figure 2 shows the modeling of the network. 


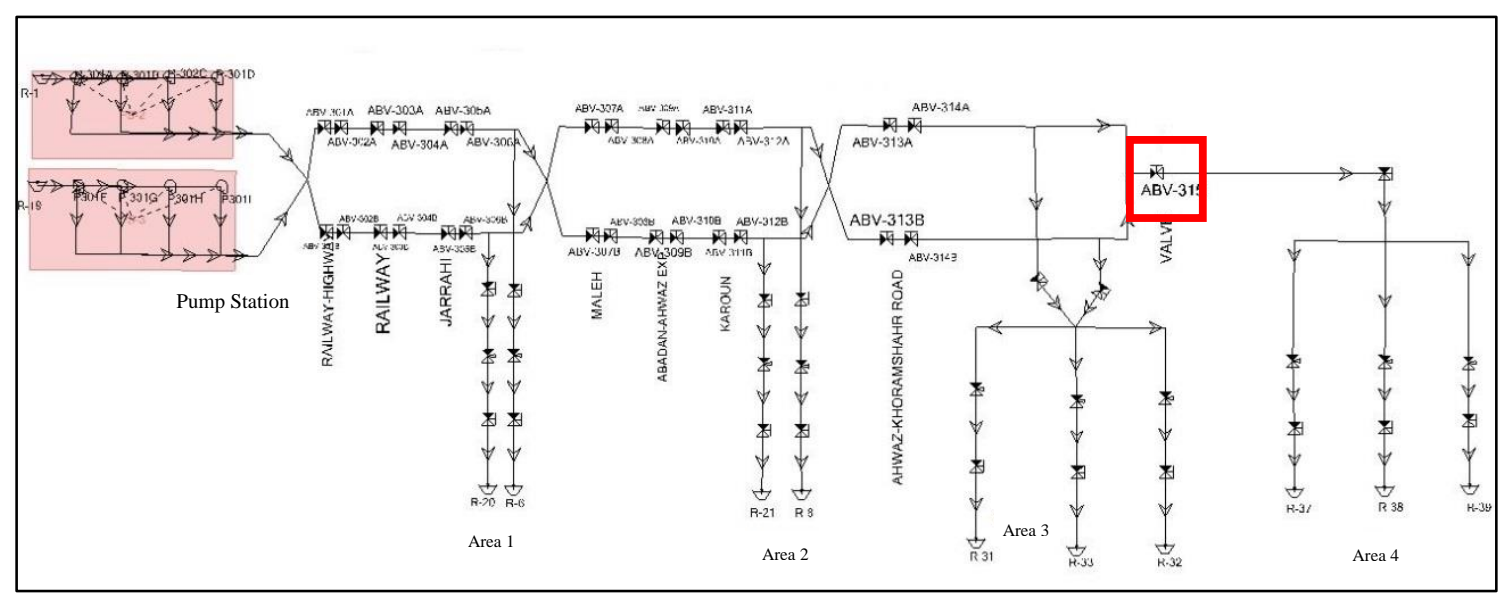

Figure 2- View of network modeling in HAMMER V8i environment

\section{2-3-2- Different scenarios}

The ABV-315 valve (shown in Figure 2) with different closing rates is considered to discuss the effect of valve closing rate on water transmission lines. The diameter of the pipe in this section is 56 inches. The investigated scenarios have to include the range of positive and negative pressure during valve closure. The closing time of the valve in different options is as shown in the table 2 .

Table 2- valve closing scenarios

\begin{tabular}{|c|c|}
\hline Scenarios & Closing time (closing rate) \\
\hline Scenario 1 & $28 \mathrm{~s}(2 \mathrm{in} / \mathrm{s})$ \\
\hline Scenario 2 & $56 \mathrm{~s}(1 \mathrm{in} / \mathrm{s})$ \\
\hline Scenario 3 & $112 \mathrm{~s}(0.5 \mathrm{in} / \mathrm{s})$ \\
\hline Scenario 4 & $224 \mathrm{~s}(0.25 \mathrm{in} / \mathrm{s})$ \\
\hline Scenario 5 & $448 \mathrm{~s}(0.125 \mathrm{in} / \mathrm{s})$ \\
\hline Scenario 6 & $560 \mathrm{~s}(0.1 \mathrm{in} / \mathrm{s})$ \\
\hline
\end{tabular}

\section{3- RESULTS AND DISCUSSION}

\section{3-1- Comparing the Scenarios}

Figure 3 shows the pressure and height diagrams obtained from the simulation of the system in a steady-state conditions. 


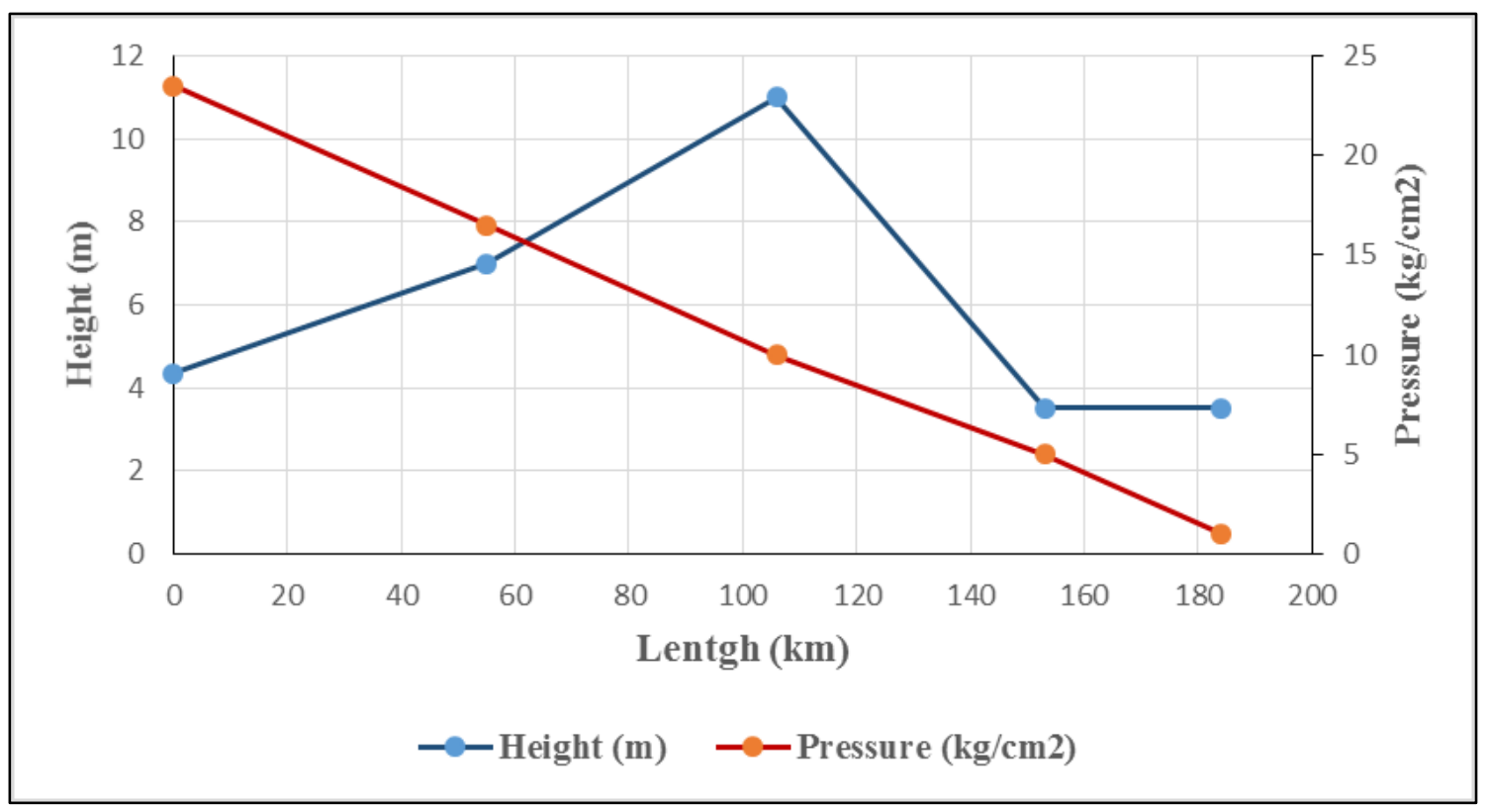

Figure 3- Graph of pressure and height along the line in steady-state conditions

Figure 4 shows the minimum pressure diagram for valve closing scenarios along the line. The minimum pressure created in each case is different. These differences are more at the valve point. As the closing rate slowed down, the minimum pressure at this point increased and proceeded to the positive region. Finally, the minimum pressure in scenario $6(560 \mathrm{~s})$ reached the positive region.

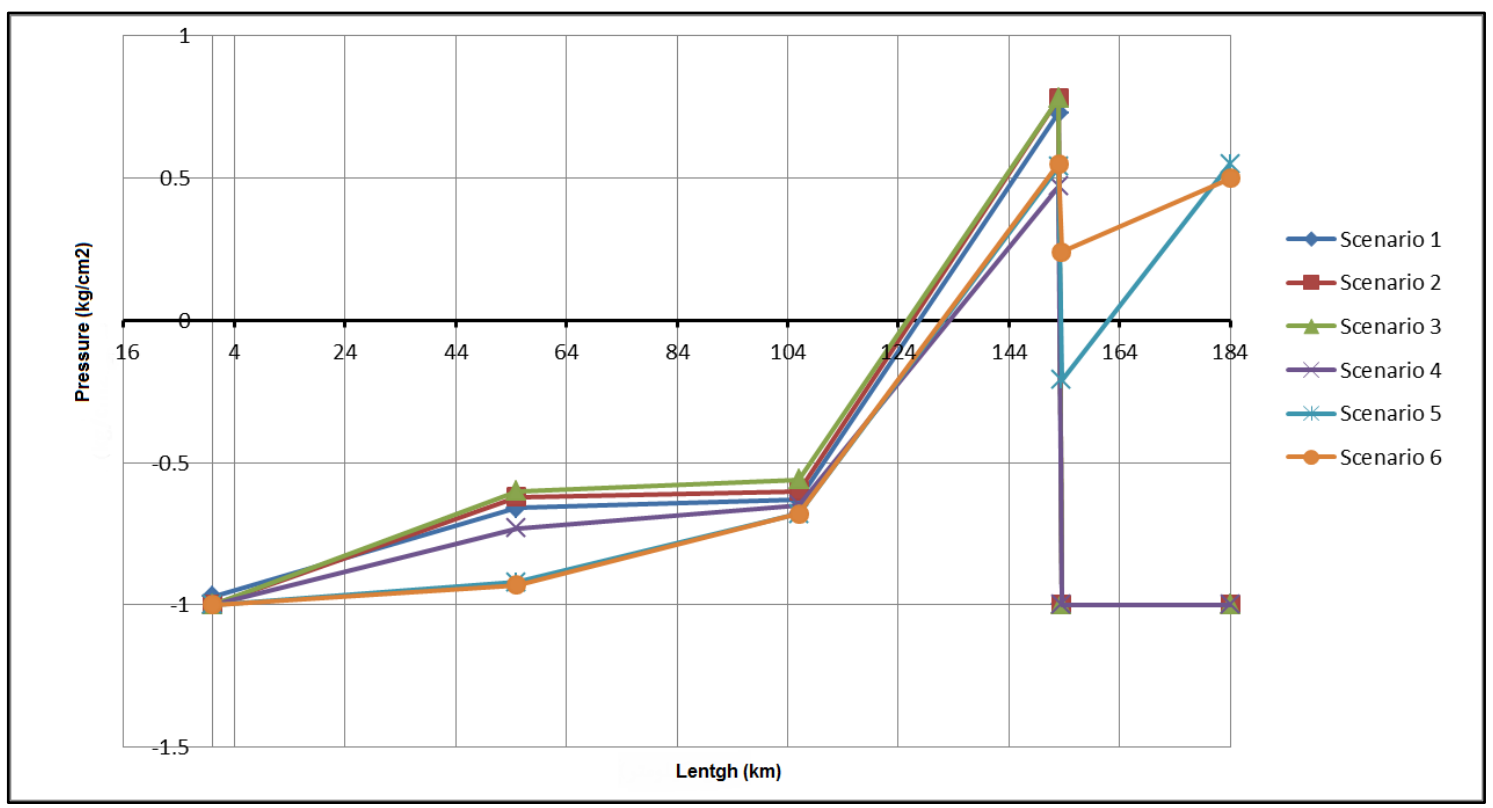

Figure 4 - Diagram of minimum pressure along the line for different scenarios 
Figure 5 shows the diagram of maximum pressure along the line. The maximum pressure created in each scenario is also a function of the closing rate of the valve. As shown in Figure 5, the maximum flow pressure is similar to the steady-state conditions as the valve closing rate decreases.

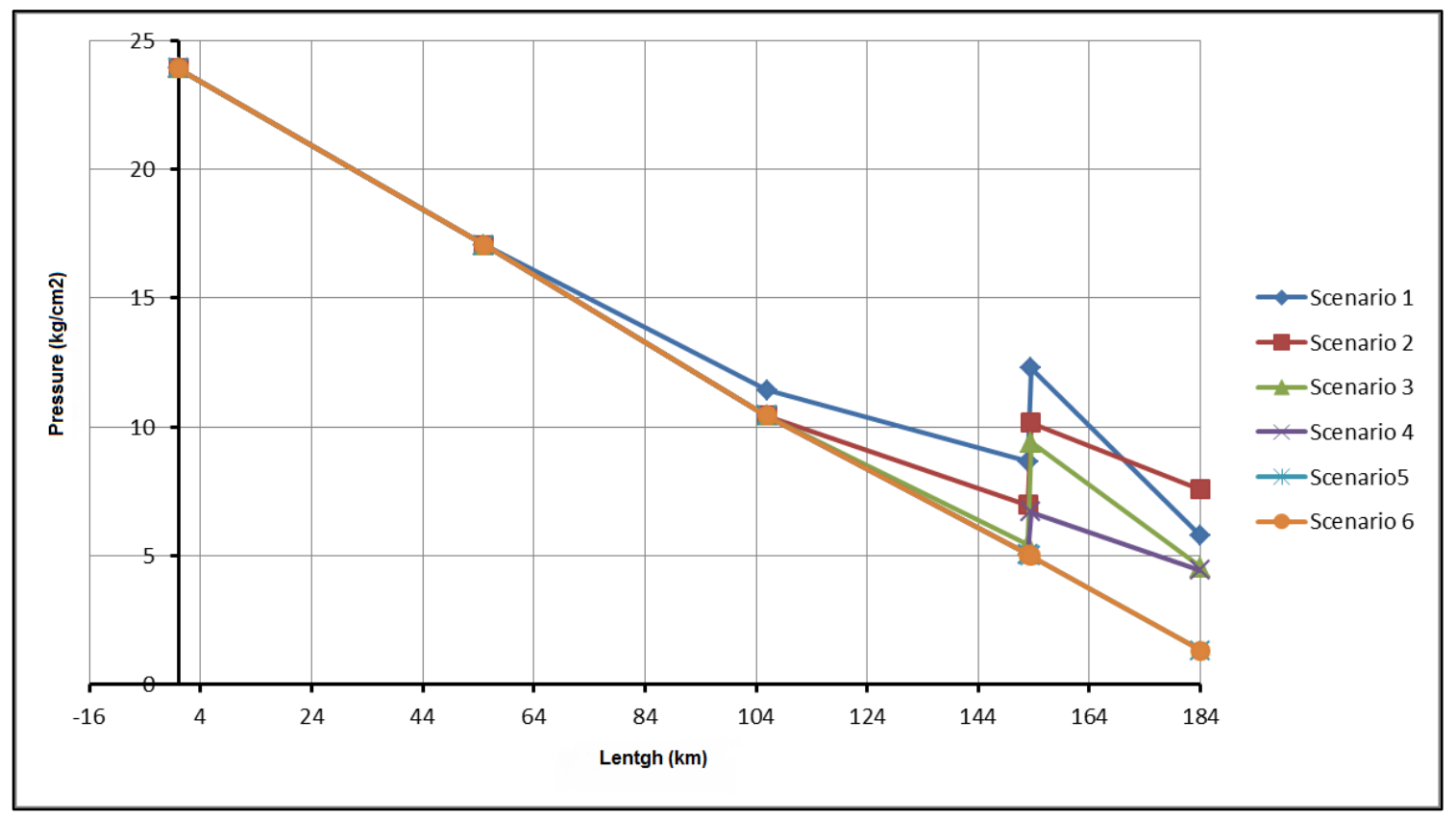

Figure 5- Diagram of maximum pressure along the line for different scenarios

Figure 6 shows the time of the first negative pressure at the valve location for different scenarios compared to the total closing time (Scenario 6 didn't create a positive or negative pressure when the valve closed in 560 seconds). 


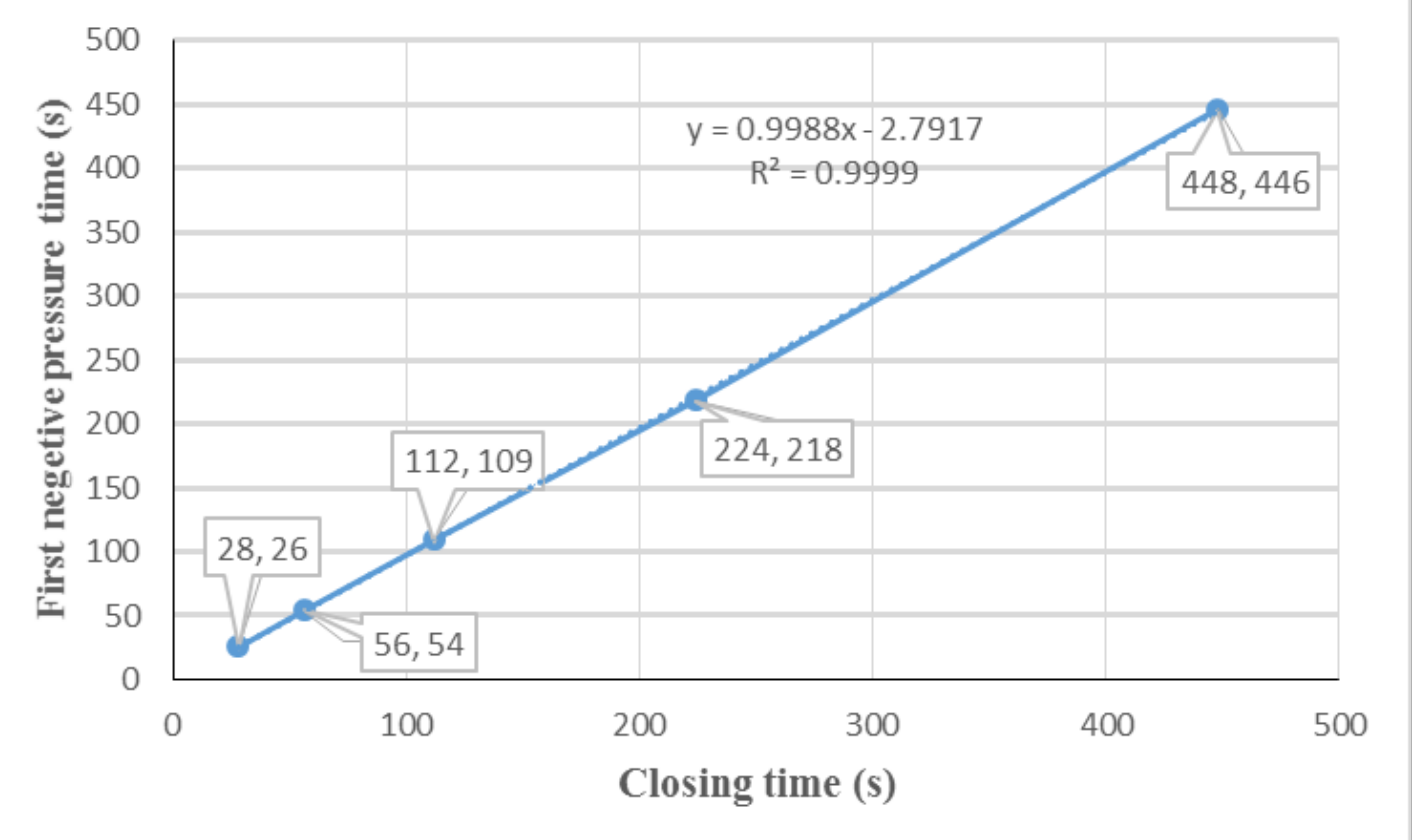

Figure 6- Time of the first negative pressure at the valve location for different scenarios

The following linear regression equation shows the relationship between these times.

$\mathrm{y}=0.9988 \mathrm{x}-2.7917$

Where $\mathrm{y}$ is the time of the first negative pressure and $\mathrm{x}$ is the total closing time.

Table 3 shows the required capacity values of the air chambers according to the minimum pressure created in each scenario.

Table 3- air chamber capacity in 6 scenarios

\begin{tabular}{|c|c|c|}
\hline Scenario & $\begin{array}{l}\text { Closing time } \\
\text { (closing rate) }\end{array}$ & $\begin{array}{l}\text { Air chamber } \\
\text { capacity* }\left(\mathrm{m}^{3}\right)\end{array}$ \\
\hline Scenario 1 & $28 \mathrm{~s}(2 \mathrm{in} / \mathrm{s})$ & 115 \\
\hline Scenario 2 & $56 \mathrm{~s}(1 \mathrm{in} / \mathrm{s})$ & 80 \\
\hline Scenario 3 & $112 \mathrm{~s}(0.5 \mathrm{in} / \mathrm{s})$ & 70 \\
\hline Scenario 4 & $224 \mathrm{~s}(0.25 \mathrm{in} / \mathrm{s})$ & 50 \\
\hline Scenario 5 & $448 \mathrm{~s}(0.125 \mathrm{in} / \mathrm{s})$ & 5 \\
\hline
\end{tabular}

* The percentage of initial air inside the chamber were considered $15 \%$.

Figure 7 shows a diagram of gas (air) variations inside the air chamber of each scenario. 


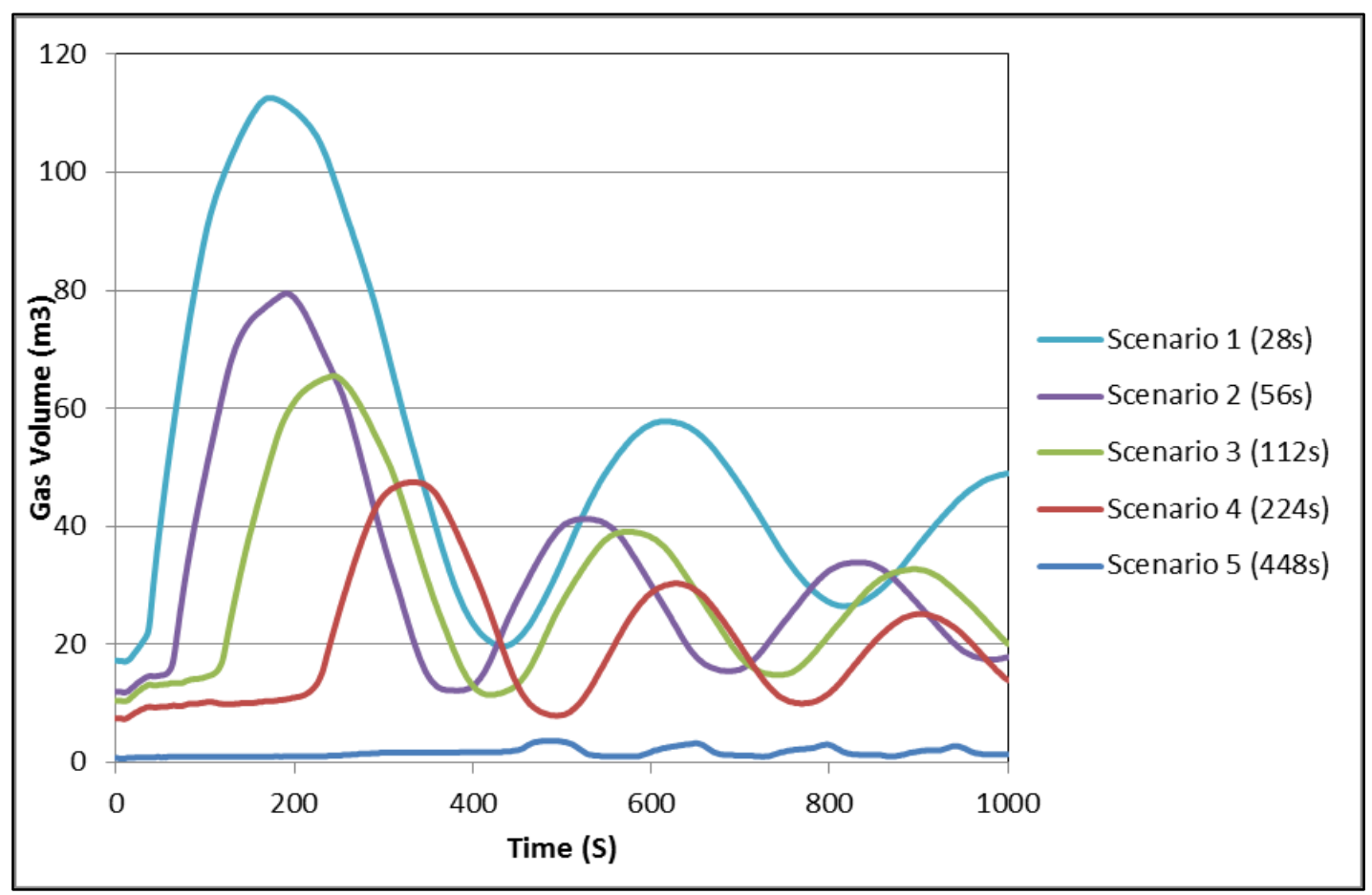

Figure 7- diagram of gas variations inside the air chamber of each scenario

As shown in Figure 7, increasing the closing time of the valve reduced the variations in gas volume and delayed the start of the first oscillation.

Optimal selection of the closing rate for LBV requires simultaneous attention to the construction cost of the air chamber and the environmental hazards resulting from the amount of water leaving the system. As the closing rate of the valve reduces, the volume of the air chamber decreases, but the amount of water entering the surrounding and its resulting environmental hazards increase. Therefore, the optimal model for construction costs and environmental hazards is obtained by comparing the capacity of the air chamber and the amount of water leaving the system in the proposed scenarios. Figure 8 shows the diagram of the air chamber capacity and the amount of discharged water in 6 scenarios. 


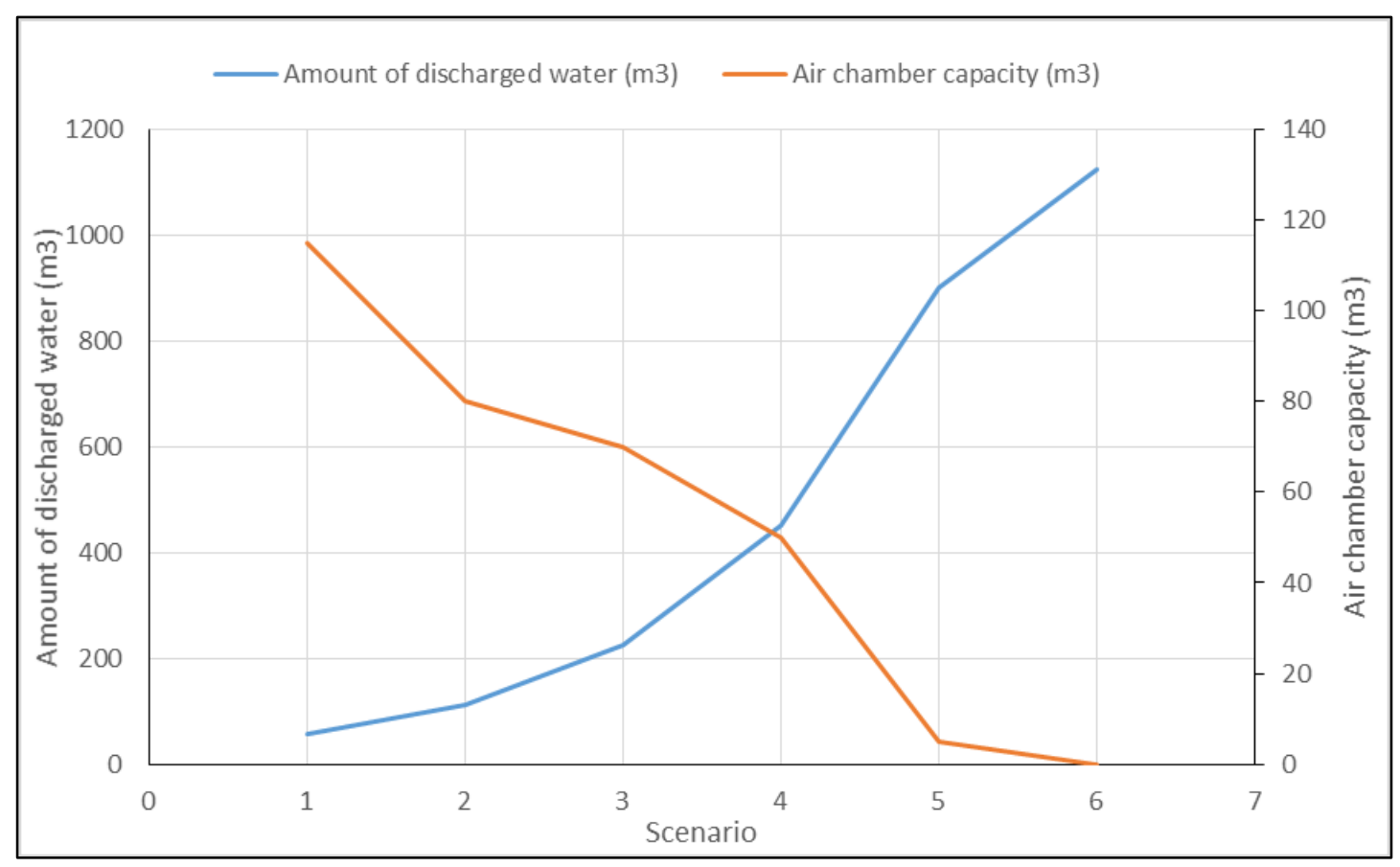

Figure 8 - the amount of discharged water and air chamber capacity in each scenario

According to the above diagram, the optimal point for the amount of discharged water and air chamber capacity is scenario 4, in which the closing time of the valve is $224 \mathrm{~s}$, air chamber capacity is $50 \mathrm{~m}^{3}$, and the amount of discharged water is $450 \mathrm{~m}^{3}$.

\section{4- CONCLUSION}

In this research, primarily hydraulic modeling of transmission lines was performed using WaterGEMS V8i, and then the mechanism of water hammer in pipes was studied by Hammer V8i. Six scenarios for valve closing rate were investigated to cover the range of positive to negative pressure during valve closing. In 560 seconds, the negative pressure resulting from the valve closure disappeared. The relationship between the time of the first negative pressure and the total closing time of the valve was a linear relationship that in a longer closing time, the time of first negative pressure was also higher. Also, the capacity of air chambers for each scenario has been studied. By reducing the closing rate of the valve, the volume of the air chambers significantly reduced. Besides, it was observed that with decreasing the closing rate, the amplitude of oscillations in the air chamber reduced, and the beginning of the first oscillation had a longer delay. Reducing the closing rate led to a reduction in the capacity of the air chamber and a cost reduction. However, consider that this reduction in closing rate increases the amount of discharged water and environmental hazards. Therefore, the optimal model is according to the capacity of the air chamber and the amount of discharged water. As a result, the optimal closing mode for line break valves was obtained 224 seconds. 


\section{REFERENCES}

Afshar, M. H., and M. Rohani. 2008, "Water hammer simulation by implicit method of characteristic", International Journal of Pressure Vessels and Piping, Volume 85, Issue 12 , Pages 851-859, https://doi.org/10.1016/j.ijpvp.2008.08.006

Bouaziz, M.A. 2014, "Water hammer effects on a gray cast iron water network after adding pumps.” Engineering Failure Analysis, Volume 44, 2014, Pages 1-16

Covas, D., I. Stoianov, H. Ramos, N. Graham, and C. Maksimovic. 2004. "The dynamic effect of pipe-wall viscoelasticity in hydraulic transients. Part I- experimental analysis and creep characterization." Journal of Hydraulic Research. Vol. 42, No. 5, pp. 516-530. https://doi.org/10.1080/00221686.2004.9641221

Covas, D., I. Stoianov, J. F.Mano, H. Ramos, N. Graham, and C. Maksimovic. 2005. "The dynamic effect of pipe-wall viscoelasticity in hydraulic transients. Part II- model development, calibration and verification." Journal of Hydraulic Research. Vol. 43, No. 1, pp. 56-70. https://doi.org/10.1080/00221680509500111

EL-Turki, A. 2013. "Modeling of Hydraulic Transients in Closed Conduits." Master's thesis, Colorado State University, Colorado.

Hawkins, G.B., 2017. "Introduction to pressure surge in liquid Systems." GBHE-PEG-FLO305, Process Engineering Guide, www.GBHenterprises.com

Mylapilli, L.K., Ph.Vital Reddy Gogula, and A. K. Arya. 2015. "Hydraulic and Surge Analysis in a Pipeline Network using Pipeline Studio." International Journal of Engineering Research and Techhnology, 4.

No.517. 2010, "Instruction for Selection \& Design of Water Hammer Facilities In Urban Water Supply." Islamic Republic of Iran Vice Presidency for Strategic Planning and Supervision. 
No.529. 2010. "Guideline for Selection of Type, Location, and Operation of Valves for Waterworks." Islamic Republic of Iran vice Presidency for Strategic Planning and Supervision.

OpenFlows HAMMER. 2020, $\leq$ https://perma.cc/3Y62-PJ7D> (Nov. 5, 2020).

OpenFlows WaterGEMS. 2020, $\leq$ https://perma.cc/633Z-X55D> (Nov. 5, 2020).

Triki, A. 2017. "Water-Hammer Control in Pressurized-Pipe Flow Using a Branched Polymeric Penstock." Journal of Pipeline Systems Engineering and Practice, Volume 8, Issue 4, https://doi.org/10.1061/(ASCE)PS.1949-1204.0000277

Wang, C., and J.Yang, 2015, "Water Hammer Simulation Using Explicit-Implicit Coupling Methods." Journal of Hydraulic Engineering, Volume 141, Issue 4, https://doi.org/10.1061/(ASCE)HY.1943-7900.0000979

Wichowski, R. 2006. "Hydraulic Transients Analysis in Pipe Networks by the Method of Characteristics (MOC)." Archives of Hydro-Engineering and Environmental Mechanics, Vol. 53 (2006), No. 3, pp. 267-291. 